Revisitando a Berceo

Lecturas del siglo XXI

Francisco Domínguez Matito

y Elisa Borsari, eds.
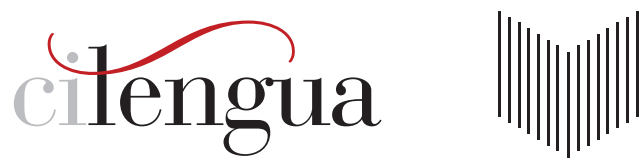


\title{
MEDIEVALIA HISPANICA
}

Fundador y director Maxim Kerkhof

\author{
Vol. 28
}

Consejo editorial

Vicenç Beltran

“La Sapienza” Università di Roma

Hugo Bizzarri

Université de Fribourg

Elisa Borsari

Universidad de La Rioja

Patrizia Botta

"La Sapienza" Università di Roma

Antonio Cortijo Ocaña

University of California, Santa Barbara

María Teresa Echenique Elizondo

Universidad de Valencia

Michael Gerli

University of Virginia

Ángel Gómez Moreno

Universidad Complutense, Madrid

Georges Martin

Université Paris-Sorbonne

Regula Rohland de Langbehn

Universidad de Buenos Aires

Julian Weiss

King's College, London 



\section{Revisitando a Berceo Lecturas del siglo XXI}

Francisco Domínguez Matito

Elisa Borsari, eds.

Iberoamericana $\bullet$ Vervuert $\bullet$ Cilengua $\bullet 2020$ 
Este trabajo se enmarca dentro de las actividades del proyecto $\mathrm{I}+\mathrm{D}+\mathrm{i}$

DHuMAR "Digital Humanities, Middle Ages \& Renaissance. 1. Poetry 2. Translation" (MINECO, FFI2013-44286-P).

La edición ha sido realizada gracias al Centro Internacional de Investigación de la Lengua Española (Fundación San Millán de la Cogolla), a la Posdoctoral Talento 2016 (Universidad de La Rioja-Comunidad Autónoma de La Rioja) y a la Cátedra de Español (UR-Banco de Santander).

Cualquier forma de reproducción, distribución, comunicación pública o transformación de esta obra solo puede ser realizada con la autorización de sus titulares, salvo excepción prevista por la ley. Diríjase a CEDRO (Centro Español de Derechos Reprográficos) si necesita fotocopiar o escanear algún fragmento de esta obra (www.conlicencia.com; 917021970 / 9327204 47).

(C) Iberoamericana, 2020

Amor de Dios, 1 - E-28014 Madrid

Tel.: +34914293522 - Fax: +34914295397

(C) Vervuert, 2020

Elisabethenstr. 3-9 - D-60594 Frankfurt am Main

Tel.: +49695974617 - Fax: +49695978743

(C) Cilengua. Fundación San Millán de la Cogolla, 2020

Plaza del Convento, s/n, E-26226

San Millán de la Cogolla (La Rioja)

Tel.: +34941373389 - Fax: +34941373390

info@iberoamericanalibros.com

www.iberoamericana-vervuert.es

978-84-9192-073-1 (Iberoamericana)

978-3-96456-863-2 (Vervuert)

978-84-17107-97-0 (Cilengua)

978-3-96456-864-9 (e-book)

Depósito Legal: M-252-2020

Diseño de cubierta: Rubén Salgueiros

Impreso en España

The paper on which this book is printed meets the requirements of ISO 9706 
